\title{
The Effect of Florida Medicaid's State-Mandated Formulary Provision on Prescription Drug Use and Health Plan Costs in a Medicaid Managed Care Plan
}

\author{
Kiraat D. Munshi, PhD; Douglas Mager, MA; Krista M. Ward, MBA; \\ Brian Mischel, RPh, MBA; and Rochelle R. Henderson, PhD
}

\begin{abstract}
BACKGROUND: Formulary or preferred drug list (PDL) management is an effective strategy to ensure clinically efficient prescription drug management by managed care organizations (MCOs). Medicaid MCOs participating in Florida's Medicaid program were required to use a state-mandated PDL between May and August 2014.
\end{abstract}

OBJECTIVE: To examine differences in prescription drug use and plan costs between a single Florida Medicaid managed care (MMC) health plan that implemented a state-mandated PDL policy on July 1, 2014, and a comparable MMC health plan in another state without a state-mandated PDL, controlling for sociodemographic confounders.

METHODS: A retrospective analysis with a pre-post design was conducted using deidentified administrative claims data from a large pharmacy benefit manager. The prepolicy evaluation period was January 1 through June 30, 2014, and the postpolicy period was January 1 through June 30, 2015. Continuously eligible Florida MMC plan members were matched on sociodemographic and health characteristics to their counterparts enrolled in a comparable MMC health plan in another state without a state-mandated formulary. Outcomes were drug use, measured as the number of 30-day adjusted nonspecialty drug prescriptions per member per period, and total drug plan costs per member per period for all drugs, with separate measures for generic and brand drugs. Bivariate comparisons were conducted using t-tests. Employing a difference-in-differences (DID) analytic approach, multivariate negative binomial regression and generalized estimating equation models were used to analyze prescription drug use and costs.

RESULTS: The final analytical sample consisted of 18,372 enrollees, evenly divided between the 2 groups. In the postpolicy evaluation period, overall and generic use declined, while brand use increased for members in the Florida health plan. Drug costs, especially for brands, significantly increased for Florida health plan members. No significant changes were observed over the same time period in the control health plan members. DID analyses indicated that the decline in overall drug use was $6 \%$ lower $(P=0.020)$, and the increase in plan costs was $27 \%$ higher $(P=0.002)$ among Florida health plan members compared with control group members.

CONCLUSIONS: Members in a Florida Medicaid health plan with a statemandated PDL saw declines in overall and generic drug use and an increase in drug plan costs. States considering a state-mandated PDL should take into account potential effects of decreased generic drug use and increases in prescription drug plan costs.

J Manag Care Spec Pharm. 2018;24(2):124-31

Copyright $\odot 2018$, Academy of Managed Care Pharmacy. All rights reserved.

\section{What is already known about this subject}

Medicaid prescription drug spending has been steadily increasing over the past few years, partly driven by increased enrollment due to Medicaid expansion.

Managed care organizations have successfully leveraged utilization management tools such as drug formularies to ensure access to clinically efficient and affordable medications for patients.

Some states, such as California and Washington, are exploring state-mandated preferred drug lists (PDLs) or formularies as a way to offset some of their prescription drug spend through additional rebates from drug manufacturers.

\section{What this study adds}

Among the Florida Medicaid managed care health plan members examined in this study, a greater decline in postpolicy period prescription drug use and a larger increase in postpolicy period drug costs were found when compared with a matched cohort of members in a comparable Medicaid health plan from another state. This study provides evidence that state-mandated PDLs may have unintended consequences of decreasing prescription drug usage, especially for generics, and increasing plan costs among Florida Medicaid members.

$\mathrm{M}$ edicaid is the largest health insurance program for Americans with limited incomes, covering an estimated 75 million beneficiaries in 2017, along with the Children's Health Insurance Program (CHIP). ${ }^{1}$ Medicaid's national prescription drug spending, not accounting for rebates, was $\$ 42.3$ billion in 2014 , an increase of $15.9 \%$ from $\$ 36.5$ billion spent in 2011. ${ }^{2}$ Total Medicaid drug spending within Medicaid managed care has increased significantly, from $\$ 5.1$ billion in 2011 to $\$ 19.7$ billion in $2014 .^{2}$ As of July 2016, 37 states had more than half of their Medicaid population enrolled in Medicaid managed care plans, with Medicaid managed care penetration rates of over $80 \%$ in 21 states. $^{3}$

Formulary management is an effective strategy used in the management of pharmacy benefit that gives states or health plans leverage in negotiating prices with pharmaceutical manufacturers. ${ }^{4,5}$ Formularies or preferred drug lists (PDLs) are 
used to promote appropriate pharmacotherapy for improving or maintaining health while encouraging cost-effective and/or clinically efficient use of medications. ${ }^{6}$ By limiting medication selection among therapeutically similar agents, PDLs enhance the ability of payers to achieve cost savings. ${ }^{7,8}$ PDLs can be designed to incentivize patients to use formulary agents (i.e., generic and preferred brands) by using a tiered benefit design for preferred and nonpreferred drugs. ${ }^{9}$

To ensure Medicaid coverage of their drugs, drug manufacturers are required to pay rebates for covered outpatient drugs reimbursed under Medicaid through the federal Medicaid Drug Rebate Program (MDRP). Before the 2010 Affordable Care Act (ACA), drugs dispensed by Medicaid managed care organizations (MCOs) were exempt from rebate requirements. However, provisions in the ACA expanded the Medicaid rebate program to include drugs dispensed by Medicaid MCOs to be eligible for rebates from drug manufacturers. ${ }^{10}$ The policy change prompted some states to require the MCOs that they contract with to implement a single Medicaid PDL that is designed by the state. By designing and managing their own PDLs, states receive supplemental rebates directly from manufacturers for drugs covered on their PDLs, along with the federal rebates as part of the MDRP.

In 2011, the Florida legislature passed HB 71072, creating the Statewide Medicaid Managed Care (SMMC) program, an integrated managed care program for Medicaid enrollees. Florida stipulated that the 20 Medicaid managed care plans participating in the SMMC program-and covering over 90\% of the state Medicaid population-implement a state-mandated PDL between May and August 2014. The legislation also created guidelines for utilization management programs such as prior authorization requirements rather than allowing MCOs to maintain their own utilization management strategies as they had in the past. ${ }^{11}$

Implementation of the state-mandated PDL was phased in by region between May 1 and August 1, 2014. Early reports following implementation of the state-mandated PDL policy starting in mid-June 2014 indicated that Medicaid MCOs serving Florida incurred monetary losses after the state-mandated PDL policy was implemented due to higher than expected prescription drug plan costs. ${ }^{12}$

To our knowledge, there is no empirical evidence examining the effect of a switch to a state-mandated PDL on prescription drug use and health plan costs among Florida health plan members. This study examined changes in drug use and plan costs for members in a Florida Medicaid health plan after the state-mandated PDL policy implementation, compared with members enrolled in a similar health plan in another state where no such policy was implemented (control group). We hypothesized that after policy implementation, generic use would decline and brand drug use would increase to a greater extent among Florida health plan members compared with the control group. Moreover, increases in Florida health plan costs would be significantly higher than those of the comparable health plan.

\section{Methods}

\section{Study Design and Population Groups}

This study was a retrospective claims analysis with a pre-post design using deidentified pharmacy claims data from a large national pharmacy benefits manager between January 1, 2014, and June 30, 2015. The Florida Medicaid managed care plan, which was the only one available for examination in this study for the entire study period, implemented the state-mandated PDL on July 1, 2014. The prepolicy period for this study was from January 1 to June 30, 2014, and the postpolicy period was from January 1 to June 30, 2015. The reasons for a 6-month gap between the 2 periods were (a) to ensure that pharmacy benefit management changes and any resulting changes in outcomes take effect, and (b) to account for any seasonal variations by comparing the outcomes over the same duration of the 2 years examined. A comparable health plan was chosen based on the provision of Medicaid managed care services in another state without any state-mandated PDL policy and the implementation of similar utilization management/prior authorization programs to the Florida Medicaid health plan. The final comparable health plan chosen was administered in a different state by the same health plan as the Florida health plan, resulting in both plans having similar utilization management/prior authorization programs.

Temporary Assistance for Needy Families (TANF) group members enrolled in the Florida Medicaid managed care health plan and the comparable Medicaid health plan were examined in this study. Members in other Medicaid groups such as CHIP; Aged, Blind and Disabled (ABD); dual-eligible beneficiaries; and those aged 65 years or older were excluded. The PDL provisions did not apply to CHIP members, and sample sizes of other Medicaid enrollment categories were too small to merit inclusion. Members in both groups had to be continuously eligible during the pre- and postpolicy evaluation periods to be included in this study.

Members in the Florida health plan who met the inclusion criteria were matched to members in the comparable health plan using a one-to-one greedy matching technique on the covariates listed in the following section. The greedy matching SAS Macro developed by statisticians at the Mayo Clinic was used to match members in the Florida and comparable health plans. ${ }^{13} \mathrm{~A}$ maximum absolute difference of 4 years in age, 2 units in disease burden score, and $\$ 4,000$ in median family income were allowed for a valid match between members of the 2 health plans. The analysis was limited to members with $\$ 0$ copay for any drug, since a majority of members in both Medicaid health plans did not have any copay associated with their prescriptions. 
The Effect of Florida Medicaid's State-Mandated Formulary Provision on

Prescription Drug Use and Health Plan Costs in a Medicaid Managed Care Plan

TABLE 1 Baseline Comparison of Member Characteristics Across Study Groups

\begin{tabular}{|c|c|c|c|c|c|c|c|}
\hline \multicolumn{8}{|c|}{ Before Matching } \\
\hline & \multicolumn{3}{|c|}{ Florida Health Plan } & \multicolumn{3}{|c|}{ Comparable Health Plan } & \multirow[b]{2}{*}{$P$ Value $^{\mathrm{a}}$} \\
\hline & n & $\begin{array}{l}\text { Mean or } \\
\text { Percentage }\end{array}$ & SD & $\mathbf{n}$ & $\begin{array}{l}\text { Mean or } \\
\text { Percentage }\end{array}$ & SD & \\
\hline Mean age, years & 13,839 & 12.54 & 12.07 & 12,427 & 13.44 & 10.97 & $<0.001$ \\
\hline Female, \% & 7,140 & 51.60 & - & 7,216 & 58.07 & - & $<0.001$ \\
\hline Disease burden proxyb & 13,839 & 3.19 & 3.83 & 12,427 & 3.52 & 3.89 & $<0.001$ \\
\hline Median household income, $\$$ & 13,839 & $24,055.80$ & $5,855.90$ & 12,427 & $21,700.40$ & $5,090.30$ & $<0.001$ \\
\hline \multicolumn{8}{|c|}{ After One-to-One Greedy Matching } \\
\hline & \multicolumn{3}{|c|}{ Florida Health Plan } & \multicolumn{3}{|c|}{ Comparable Health Plan } & \\
\hline & $\mathrm{n}$ & $\begin{array}{l}\text { Mean or } \\
\text { Percentage }\end{array}$ & SD & n & $\begin{array}{l}\text { Mean or } \\
\text { Percent }\end{array}$ & SD & $P$ Value \\
\hline Mean age, years & 9,186 & 11.61 & 8.63 & 9,186 & 11.72 & 8.60 & 0.421 \\
\hline Female, \% & 4,990 & 54.33 & - & 4,990 & 54.33 & - & 1.000 \\
\hline Disease burden proxy ${ }^{b}$ & 9,186 & 2.85 & 2.82 & 9,186 & 2.94 & 2.85 & 0.081 \\
\hline Median household income, \$ & 9,186 & $22,206.80$ & $4,575.50$ & 9,186 & $22,114.80$ & $4,569.50$ & 0.148 \\
\hline \multicolumn{8}{|c|}{$\begin{array}{l}\text { aIn the unmatched sample, t-tests were conducted for continuous variables, and a chi-square test was conducted for the categorical variable. Numbers in bold indicate sta } \\
\text { tistical significance at } P<0.05 \text {. } \\
\text { bDisease burden proxy was defined as a unique count of 2-digit GPIs for all prescriptions used by the patient. } \\
\text { IIn the matched sample, paired } t \text {-tests were conducted for continuous variables, and McNemar's test was conducted for the categorical variable. } \\
\text { GPI = Generic Product Identifier; SD = standard deviation. }\end{array}$} \\
\hline
\end{tabular}

\section{Study Variables}

Health plan (Florida health plan vs. comparable health plan) was the main independent variable. This enabled evaluation of whether switching to a state-mandated PDL policy affected prescription drug use and drug plan costs. The following covariates were used to match members in the Florida health plan who met the inclusion criteria to those in the comparable health plan using a one-to-one greedy matching algorithm: age (in years) as of January 1, 2014; gender; disease burden proxy score; and median family income at the residential ZIP code level. A member's overall disease burden score was calculated by summing the number of unique first 2-character subsets of the Generic Product Identifiers (GPIs) associated with all prescription drugs used by members during the study period. The score generated indicated the number of distinct drug therapy classes used by a member. This measure has been used previously. ${ }^{14}$

Outcomes included prescription drug use and drug plan costs. This study examined prescription drug claims for all traditional (nonspecialty) drugs. Since less than $2 \%$ of members used specialty drugs in both plans, they were excluded from this study. Traditional drugs do not have specialized handling, storage, or administration requirements. Medications were subdivided into generic and brand drugs (formulary and nonformulary brands). Usage was defined as the total number of 30-day adjusted prescription claims per member. Plan cost was defined as the summation of ingredient costs, taxes, dispensing fees, and administrative fees. Rebates to MCOs or states were not included in this study. The authors did not have access to the federal drug rebates information, since detailed rebate rate or collection information is not available publicly. In addition, states do not publicize the rebates they earn from manufacturers. As a result, the plan costs examined in this study are not net of rebates. For each member, usage and plan costs were summed in the pre- and postpolicy periods.

\section{Statistical Analysis}

Differences in baseline characteristics in the unmatched sample were analyzed using t-tests for continuous variables and the chi-square test for the categorical variable. Baseline differences in the matched sample were examined using a paired t-test and McNemar's test. All outcome measures in the bivariate analysis were examined using a paired t-test. Multivariate negative binomial regression analysis was conducted to evaluate changes in drug use and multivariate generalized estimating equation regression with gamma distribution and log link was used to evaluate changes in drug plan costs.

A multivariate difference-in-differences (DID) analytic approach was used when examining changes in prescription drug use and drug plan costs. This approach compared changes in prescription drug use and health plan costs over time (postpolicy vs. prepolicy periods) across the 2 study groups (Florida health plan vs. comparable health plan) by including an interaction term between the plan and period variables. Six separate DID analytic models were created: 3 for utilization (overall, generic, and brand drug use) and 3 for plan cost outcomes (overall, generic, and brand drug plan costs). 
TABLE 2 Bivariate Comparison of Per Member Drug Use and Plan Costs Between Pre- and Postpolicy Periods

\begin{tabular}{|c|c|c|c|c|c|c|}
\hline & \multicolumn{2}{|c|}{ Florida Health Plan $(n=9,186)$} & \multirow[b]{2}{*}{$P$ Value ${ }^{a}$} & \multicolumn{2}{|c|}{ Comparable Health Plan $(n=9,186)$} & \multirow[b]{2}{*}{$P$ Value ${ }^{a}$} \\
\hline & Mean & SD & & Mean & SD & \\
\hline \multicolumn{7}{|c|}{ Utilization (number of 30-day adjusted prescriptions) } \\
\hline \multicolumn{7}{|c|}{ All drugs } \\
\hline Preperiod & 2.35 & 0.06 & $<0.001$ & 2.49 & 5.68 & 0.457 \\
\hline Postperiod & 2.09 & 0.05 & & 2.45 & 5.70 & \\
\hline \multicolumn{7}{|c|}{ Generic drugs } \\
\hline Preperiod & 2.16 & 0.06 & $<0.001$ & 2.18 & 4.81 & 0.380 \\
\hline Postperiod & 1.87 & 0.05 & & 2.14 & 4.82 & \\
\hline \multicolumn{7}{|l|}{ Brand drugs } \\
\hline Preperiod & 0.18 & 0.01 & $<0.001$ & 0.30 & 1.41 & 0.831 \\
\hline Postperiod & 0.23 & 0.01 & & 0.30 & 1.46 & \\
\hline \multicolumn{7}{|l|}{ Plan costs, \$ } \\
\hline \multicolumn{7}{|l|}{ All drugs } \\
\hline Preperiod & 63.68 & 2.88 & $<0.001$ & 63.10 & 324.00 & 0.091 \\
\hline Postperiod & 82.19 & 3.73 & & 68.25 & 302.60 & \\
\hline \multicolumn{7}{|c|}{ Generic drugs } \\
\hline Preperiod & 39.27 & 1.39 & $<0.001$ & 28.98 & 82.75 & 0.278 \\
\hline Postperiod & 35.86 & 1.29 & & 29.69 & 88.59 & \\
\hline \multicolumn{7}{|l|}{ Brand drugs } \\
\hline Preperiod & 20.91 & 1.86 & $<0.001$ & 30.31 & 190.00 & 0.010 \\
\hline Postperiod & 46.30 & 3.09 & & 35.98 & 228.20 & \\
\hline
\end{tabular}

Each outcome was analyzed in separate regression models with the interaction between study group and time period as the main independent variable. All models were adjusted for age, gender, 2-level GPI count (disease burden proxy), and median household income.

Sensitivity analyses were conducted by rerunning all analytic models after including the $4 \%$ sample that had $>\$ 0$ in prescription copay in the Florida health plan, who had been excluded in the main analysis. SAS version 9.3 was used for data processing and analyses (SAS Institute, Cary, NC).

\section{Results}

In order to examine change in formulary status, a subset of prescriptions that were dispensed in the pre- and postpolicy periods for members in the Florida and comparable health plans were examined (Appendix A, available in online article). In the Florida health plan, a change in status from nonpreferred brand to preferred brand was observed for about $7 \%$ of all unique prescriptions, with no major shifts in formulary status in the comparable health plan observed over the same time period. Additional examination revealed that single-source and multi-source brands that were nonpreferred in the prepolicy period switched their status to preferred brands after policy implementation (results not shown).

\section{Descriptive Results}

The sample selection process is displayed in Appendix B (available in online article). The final matched study sample consisted of 18,372 members, with 9,186 members in both the Florida and the comparable health plans. The sample baseline characteristics before and after matching are displayed in Table 1 . Before matching, there was a significant difference between the 2 member groups $(P<0.001)$. After matching, differences in demographic and health characteristics were no longer statistically significant $(P>0.05)$.

The bivariate analysis results comparing the prepolicy and postpolicy outcome measures of drug use and plan costs among the 2 study groups are displayed in Table 2 . There was a statistically significant decline in overall drug use between the pre- and postpolicy periods among Florida Medicaid members from 2.35 to 2.09 per member for 30-day adjusted prescriptions $(P<0.001)$. In contrast, drug use did not change significantly from pre- to postpolicy periods in the comparable Medicaid health plan $(P=0.457)$. Generic drug use significantly declined $(P<0.001)$, while brand drug use significantly increased $(P<0.001)$ after policy implementation among Florida Medicaid members, with no significant corresponding usage changes in the comparison group over the same time period. Overall drug plan costs rose from $\$ 63.68$ per member in the prepolicy period to $\$ 82.19$ per member in the 


\begin{tabular}{|c|c|c|c|c|}
\hline \multirow[t]{3}{*}{ TABLE 3} & \multicolumn{4}{|c|}{$\begin{array}{l}\text { Multivariate Regression Analysis } \\
\text { Examining Incidence of Postperiod } \\
\text { Prescription Drug Use }\end{array}$} \\
\hline & \multicolumn{2}{|c|}{$\begin{array}{l}\text { Florida Health Plan } \\
\qquad(\mathrm{n}=9,186)\end{array}$} & \multicolumn{2}{|c|}{$\begin{array}{l}\text { Comparable Health Plan } \\
(\mathrm{n}=9,186)\end{array}$} \\
\hline & $\begin{array}{l}\text { Utilization } \beta \\
\quad(95 \% \mathrm{CI})\end{array}$ & $P$ Value & $\begin{array}{l}\text { Utilization } \beta \\
\quad(95 \% \mathrm{CI})\end{array}$ & $P$ Value \\
\hline \multicolumn{5}{|l|}{ All drugs } \\
\hline Preperiod (ref.) & - & - & - & - \\
\hline Postperiod & $-0.11(-0.15,-0.07)$ & $<0.001$ & $-0.04(-0.08,0.00)$ & 0.053 \\
\hline \multicolumn{5}{|l|}{ Generic drugs } \\
\hline Preperiod (ref.) & - & - & - & - \\
\hline Postperiod & $-0.13(-0.17,-0.09)$ & $<0.001$ & $-0.04(-0.08,0.01)$ & 0.070 \\
\hline \multicolumn{5}{|l|}{ Brand drugs } \\
\hline Preperiod (ref.) & - & - & - & - \\
\hline Postperiod & $0.22(0.10,0.34)$ & $<0.001$ & $-0.06(-0.15,0.04)$ & 0.260 \\
\hline \multicolumn{5}{|c|}{$\begin{array}{l}\text { aEach drug utilization measure was analyzed in a separate regression model with } \\
\text { time period as the main independent variable of interest. All regression models } \\
\text { were adjusted for age, gender, 2-level GPI count (disease burden proxy), and } \\
\text { median household income. Numbers in bold indicate statistical significance at } \\
P<0.05 \text {. } \\
\beta=\text { beta coefficient; } C I=\text { confidence interval; GPI = Generic Product Identifier; } \\
\text { ref. = reference. }\end{array}$} \\
\hline
\end{tabular}

postpolicy period $(P<0.001)$ in the Florida health plan, with no significant pre-post plan cost changes in the comparable health plan $(P=0.091)$. Increase in brand drug plan cost $(P<0.001)$ more than offset the decline in generic drug plan cost per member $(P<0.001)$ in the Florida health plan, which may have contributed to the rise in plan costs overall. In contrast, with the exception of brand drug plan costs, these changes were not significant among the comparable health plan members.

\section{Multivariate Analysis Results}

The multivariate results confirm the bivariate findings (Table 3 and Table 4). Overall drug use and generic use declined by $11 \%$ and $13 \%$, respectively, while brand use increased by $22 \%$ in the postpolicy period among Florida health plan members $(P<0.001)$. Overall and brand drug plan costs increased by $31 \%$ and $39 \%$, respectively, while generic plan costs declined by $8 \%$ in the postpolicy period for Florida health plan members $(P<0.010)$. In contrast, none of the changes in outcomes were significant in the comparison group.

Results from the DID analyses are displayed in Table 5. For ease of interpretation, only the beta coefficients for DID variables are displayed. The declines in overall drug $(P=0.020)$ and generic use $(P=0.001)$ were $6 \%$ and $9 \%$ lower, respectively, and increase in brand use was $27 \%$ higher $(P<0.001)$ among Florida health plan members, in contrast with the comparable health plan members. Similarly, the increases of $27 \%$ and $85 \%$ in overall drug $(P=0.002)$ and brand drug plan costs $(P<0.001)$, respectively, were significantly higher for the Florida health plan members than the respective postpolicy

\begin{tabular}{|c|c|c|c|}
\hline \multicolumn{2}{|c|}{$\begin{array}{l}\text { Florida Health Plan } \\
\quad(n=9,186)\end{array}$} & \multicolumn{2}{|c|}{$\begin{array}{l}\text { Comparable Health Plan } \\
(n=9,186)\end{array}$} \\
\hline $\begin{array}{c}\text { Plan Costs } \beta \\
(95 \% \mathrm{CI})\end{array}$ & $P$ Value & $\begin{array}{c}\text { Plan Costs } \beta \\
(95 \% \mathrm{CI})\end{array}$ & $P$ Value \\
\hline
\end{tabular}

\begin{tabular}{|c|c|c|c|c|}
\hline \multicolumn{5}{|l|}{ All drugs } \\
\hline Preperiod (ref.) & - & - & - & - \\
\hline Postperiod & $0.31(0.23,0.39)$ & $<0.001$ & $0.08(-0.03,0.17)$ & 0.055 \\
\hline \multicolumn{5}{|l|}{ Generic drugs } \\
\hline Preperiod (ref.) & - & - & - & - \\
\hline Postperiod & $-0.08(-0.13,-0.03)$ & 0.002 & $0.04(-0.02,0.10)$ & 0.184 \\
\hline \multicolumn{5}{|l|}{ Brand drugs } \\
\hline Preperiod (ref.) & - & - & - & - \\
\hline Postperiod & $0.39(0.21,0.57)$ & $<0.001$ & $0.15(-0.02,0.32)$ & 0.090 \\
\hline \multicolumn{5}{|c|}{$\begin{array}{l}\text { aEach plan cost measure was analyzed in a separate generalized linear regression } \\
\text { model with time period as the main independent variable of interest. All regression } \\
\text { models were adjusted for age, gender, 2-level GPI count (disease burden proxy), } \\
\text { and median household income. Numbers in bold indicate statistical significance at } \\
P<0.05 \text {. } \\
\beta=\text { beta coefficient; } C I=\text { confidence interval; GPI = Generic Product Identifier; } \\
\text { ref. = reference. }\end{array}$} \\
\hline
\end{tabular}

plan cost increases among the comparable health plan members. Difference in generic plan cost was not statistically significant, despite the $9 \%$ decline in the DID estimate $(P=0.126)$. Results from sensitivity analyses did not differ in directionality or significance (results not shown).

\section{Discussion}

The main objective of this study was to examine whether the implementation of a state-mandated Medicaid PDL policy in Florida affected prescription drug use or plan costs. It is the first study to our knowledge to provide empirical evidence of the effect that this policy may have had on drug use and plan costs in a Florida health plan with a state-mandated PDL. Overall drug use decreased, with the most notable drop being for generic drugs, in the postpolicy period among the Florida health plan members. Nevertheless, drug plan costs went up, as did brand drug plan costs in the postpolicy period.

Over the same time period, the changes in drug use and plan costs were not statistically significant in the control group of members with similar demographics who were enrolled in a different state's Medicaid health plan without any requirement for implementing a state-mandated PDL. Moreover, the decreases in drug use and increases in plan costs were significantly greater among the Florida health plan members compared with the control group members. Although generic plan cost differences between the 2 groups were not statistically different, the results directionally point toward a greater decline among Florida members when compared with the control group members. While not representative of the entire 


\begin{tabular}{|c|c|c|c|c|}
\hline TABL & \multicolumn{4}{|c|}{$\begin{array}{l}\text { Difference-in-Differences Analysis } \\
\text { Examining Changes in Prescription } \\
\text { Drug Use and Plan Costs Between } \\
\text { the Study Group Members }\end{array}$} \\
\hline & $\begin{array}{c}\text { Utilization } \beta \\
(95 \% \mathrm{CI})\end{array}$ & $P$ Value & $\begin{array}{c}\text { Plan Costs } \beta \\
(95 \% \mathrm{CI})\end{array}$ & $P$ Value \\
\hline All drugs & $-0.06(-0.12,-0.01)$ & 0.020 & $0.27(0.10,0.45)$ & 0.002 \\
\hline Generic drugs & $-0.09(-0.15,-0.04)$ & 0.001 & $-0.09(-0.21,0.03)$ & 0.126 \\
\hline Brand drugs & $0.27(0.11,0.42)$ & $<0.001$ & $0.85(0.50,1.19)$ & $<0.001$ \\
\hline \multicolumn{5}{|c|}{$\begin{array}{l}\text { aEach drug use and plan cost outcomes measure was analyzed in a separate gen- } \\
\text { eralized linear regression model with the interaction between study group and time } \\
\text { period as the main independent variable of interest. All regression models were } \\
\text { adjusted for age, gender, 2-level GPI count (disease burden proxy), and median } \\
\text { household income. Numbers in bold indicate statistical significance at } P<0.05 \text {. } \\
\beta=\text { beta coefficient; } C I=\text { confidence interval; GPI = Generic Product Identifier. }\end{array}$} \\
\hline
\end{tabular}

Medicaid population for any state, these results provide important insights into the effect that a state-mandated PDL policy may have, especially on members with similar demographics and number of prescriptions used.

Among the many successful tools that MCOs use to manage prescription drug benefits is clinically efficient formulary management. Additional tools such as prior authorization and step therapy are implemented after careful clinical and cost considerations for certain therapies that offer little or no additional clinical benefit over existing low-cost therapeutic alternatives. ${ }^{15}$ Mandates that preclude such strategies may weaken the ability of MCOs to appropriately manage the pharmaceutical benefits in a cost-effective manner. Our analysis of the formulary status of drugs that were dispensed in the pre- and postpolicy periods showed significant shifts in formulary status from nonpreferred brand to preferred brand for single- and multi-source brands in the Florida health plan. A possible reason for these shifts could be the supplemental rebates from pharmaceutical manufacturers. In the absence of a state-mandated PDL, MCOs design their own clinically efficient formularies and negotiate with the manufacturers for supplemental rebates. The rebates help offset the risk that MCOs take. With a state-mandated PDL in place, the state steps in to negotiate with manufacturers for formulary placement of drugs and, in this process, receive the supplemental rebates. As the results in this study have shown, generic drug use may be adversely affected if mandated formularies are relatively less managed and allow greater brand name use, possibly resulting from increased access to brand drugs on the PDL.

In addition to Florida, a few other states, including Texas, have moved to a single state-mandated Medicaid PDL. ${ }^{16}$ In a report produced on behalf of the Texas Association of Health Plans, it was found that costs per prescription, net of rebates, and brand name drug use were higher among Texas Medicaid beneficiaries when compared with other states without a mandated formulary. ${ }^{17}$ Among states where Medicaid health plans were managing prescription drug benefits for beneficiaries, prescription drug costs net of rebates were about 19\% lower than those in Texas. ${ }^{17}$ A report for the Texas Health and Human Services Commission compared total net pharmacy costs paid by Texas Medicaid with those paid by Medicaid agencies in 13 other states with no state-mandated PDL policies. ${ }^{18}$ The total net pharmacy cost was estimated to be $1.8 \%$ lower in a nonmandated scenario compared with the mandated PDL scenario in Texas. Removing the PDL mandate was estimated to result in approximately $\$ 40$ million in savings. ${ }^{18}$ While results from our study are not directly comparable, since only 1 health plan was examined and costs were not adjusted for rebates, we found significant increases of nearly $30 \%$ in prescription drug plan costs in the period after the policy was implemented.

State Medicaid agencies can generate a significant amount of savings by not only moving some or all of their population groups to managed Medicaid, but also by enabling Medicaid health plans to successfully employ all pharmacy benefit management strategies to provide optimal clinical benefits at lower costs. ${ }^{19,20}$ Some studies have found positive effects of these tools and strategies on pharmacotherapy outcomes. ${ }^{21,22}$

Additional research is needed to better understand the effect of state-mandated formularies, inclusive of federal and supplemental rebates that states receive from drug manufacturers. However, we can infer from this study that unintended consequences of decreased drug use and increased costs may result when participating Medicaid plans are unable to leverage utilization management strategies, including MCO managed formularies, to control costs and advocate for appropriate, cost-effective therapy. Reports suggest that in the face of monetary losses, Medicaid managed care plans have requested the Florida Medicaid agency to increase the capitation rates paid to the plans for managing the prescription and health benefits for enrollees..$^{12,23}$ States may be able to prevent any unforeseen effects on medication use and plan costs with mandated PDLs by taking into consideration drug use changes among beneficiaries and health plan financial viability.

\section{Limitations}

Some limitations to this study need to be considered. Because of the lack of access to federal rebates or supplemental rebates from pharmaceutical manufacturers that states receive, this study did not take into account federal rebates or rebates obtained by the state in exchange for including brand drugs in the PDL. Future research examining the costs net of rebates over a longer period may be useful in further validating the effect of state-mandated PDL policies. 
Because of sample size limitations, other Medicaid groups that were affected by the state-mandated PDL policy, such as the ABD and dual-eligible beneficiaries, were not examined. Any changes, if observed, would likely be statistically insignificant due to the small sample sizes. Future analysis should incorporate these groups, provided sufficient sample size is available, to get a broader picture of the policy effect.

Another limitation was the reduction in sample size due to matching, which resulted from removal of individuals in the study group who did not match with a suitable control. Nonetheless, nearly $70 \%$ of the individuals in the unmatched sample were included in the final matched study sample. Matching can ensure that potential differences in the outcomes observed between the 2 health plan members because of confounders are minimized; however, in the absence of randomization, confounding cannot be eliminated. In addition, unobserved differences between the study populations, such as health-seeking behavior, were not accounted for in this study.

Generalizability of findings were limited to TANF Medicaid members in Florida with similar sociodemographic characteristics to members examined in this study, and not representative of the entire Medicaid population as a whole. The effect of the formulary changes on health outcomes were not examined because of unavailability of medical data for the study population. Future studies may examine pharmacy and medical data to determine financial, as well as clinical, implications. Finally, these estimates did not account for new drugs coming into market or brand drugs losing patent protection during the time periods evaluated.

\section{Conclusions}

This study found greater decline in prescription drug use and increases in overall and brand drug plan costs among members of a Florida Medicaid health plan compared with a matched group of members enrolled in a comparable Medicaid managed care health plan in the period after a state-mandated Medicaid PDL policy was implemented in Florida. Our findings have important financial implications for states using or considering state-mandated PDL policies. States need to anticipate increased drug costs for health plans and make equitable adjustments to plan capitation rates. By ensuring that any provisions mandating drug formularies for Medicaid beneficiaries take into consideration drug use changes among beneficiaries and health plan financial viability, states may be able to prevent any unintended effects on medication use and prescription drug plan costs.

\section{Authors}

KIRAAT D. MUNSHI, PhD; DOUGLAS MAGER, MA; KRISTA M. WARD, MBA; BRIAN MISCHEL, RPh, MBA; and ROCHELLE R. HENDERSON, PhD, Express Scripts Holding Company, St. Louis, Missouri.

AUTHOR CORRESPONDENCE: Kiraat D. Munshi, PhD, Senior Outcomes Research Manager, Express Scripts Holding Company, 1640 Century Center Pkwy., Memphis, TN 38134.

E-mail:kdmunshi@express-scripts.com.

\section{DISCLOSURES}

Funding for this study was provided internally by Express Scripts Holding Company. The authors and acknowledged contributors are employees of Express Scripts Holding Company.

All authors contributed to the study concept, and study design was provided by Munshi, Mager, and Henderson. Munshi and Mager collected the data, and Munshi provided the statistical analysis. Data interpretation was performed by Munshi, Mager, and Henderson. The manuscript was written by Munshi, Henderson, and Mager and revised by Munshi, Ward, Mischel, and Henderson.

\section{ACKNOWLEDGMENTS}

The authors thank Reethi N. Iyengar, PhD, and Mark Eatherly, BA, for guidance in data acquisition and writing and Ruth Martinez, RPh, for helpful suggestions in the critical review of the manuscript.

\section{REFERENCES}

1. Gottlieb A. The steadying state of Medicaid in the United States: growth slows, the significance of private Medicaid health plans shows, \& consolidation grows. PricewaterhouseCoopers. Available at: http://www.medicaidconference.com/_images/content/2016PwC_Report.pdf. Accessed January 6, 2018.

2. Medicaid and CHIP Payment Access Commission (MACPAC). Medicaid spending for prescription drugs. Issue brief. January 2016. Available at: https://www.macpac.gov/wp-content/uploads/2016/01/Medicaid-Spendingfor-Prescription-Drugs.pdf. Accessed January 6, 2018.

3. Kaiser Family Foundation. Medicaid managed care penetration rates by eligibility group. October 13, 2016. Available at: http://kff.org/medicaid/state-indicator/managed-care-penetration-rates-by-eligibility-group/. Accessed January 6, 2018.

4. Gencarelli DM. Medicaid prescription drug coverage: state efforts to control costs. NHPF Issue Brief. 2003; (790):1-17.

5. Morden NE, Sullivan SD. States' control of prescription drug spending: a heterogeneous approach. Health Aff (Millwood). 2005;24(4):1032-38.

6. Motheral BR, Delate TA, Shaw JW, Henderson R. The effect of a closed formulary in the face of real-life enrollment and disenrollment patterns. J Manag Care Pharm. 2000;6(4):293-97. Available at: http://www.jmcp.org/ doi/abs/10.18553/jmcp.2000.6.4.293.

7. Rucker TD, Schiff G. Drug formularies: myths-in-formation. Med Care. 1990;28(10):928-42.

8. Trice S, Devine J, Mistry H, Moore E, Linton A. Formulary management in the Department of Defense. J Manag Care Pharm. 2009;15(2):133-46. Available at: http://www.jmcp.org/doi/10.18553/jmcp.2009.15.2.133.

9. Rector TS, Finch MD, Danzon PM, Pauly MV, Manda BS. Effect of tiered prescription copayments on the use of preferred brand medications. Med Care. 2003;41(3):398-406. 
10. Department of Health and Human Services, Office of Inspector General. States' collection of rebates for drugs paid through Medicaid managed care organizations. September 2012. Available at: https://oig.hhs.gov/oei/reports/ oei-03-11-00480.pdf. Accessed January 6, 2018.

11. The Florida Senate. Senate Bill 1354. Bill analysis and fiscal impact statement. March 22, 2014. Available at: https://www.flsenate.gov/Session/ Bill/2014/1354. Accessed January 6, 2018.

12. Gentry C. Medicaid HMOs losing money on drugs. Health News Florida. April 16, 2015. Available at: http://health.wusf.usf.edu/post/medicaid-hmoslosing-money-drugs\#stream/0. Accessed January 6, 2018.

13. Bergstralh E, Kosanke J. General SAS macros-gmatch. Mayo Clinic, Division of Biomedical Statistics and Informatics. October 2003. Available at: http://www.mayo.edu/research/departments-divisions/departmenthealth-sciences-research/division-biomedical-statistics-informatics/software/ locally-written-sas-macros. Accessed January 6, 2018

14. Iyengar RN, LeFrancois AL, Henderson RR, Rabbitt RM. Medication nonadherence among Medicare beneficiaries with comorbid chronic conditions: influence of pharmacy dispensing channel. J Manag Care Spec Pharm. 2016;22(5):550-60. Available at: http://www.jmcp.org/doi/10.18553/ jmcp.2016.22.5.550.

15. Joines W, Menges J, Tracey J. Programmatic assessment of carve-in and carve-out arrangements for Medicaid prescription drugs. Association for Community Affiliated Plans. October 17, 2007. Available at: http:// www.communityplans.net/Portals/0/MMC\%20Bibliography/ACAP\%20 Programmatic\%20Paper\%20102407.pdf. Accessed January 6, 2018.

16. The Menges Group. State policies regarding Medicaid MCO preferred drug lists. March 2014. Available at: http://www.communityplans.net/ Portals/0/Fact\%20Sheets/ACAP_Menges_State_PDL_Policies.pdf. Accessed January 6, 2018.
17. Texas Association of Health Plans. New TAHP study reveals potential to unlock millions in savings in Texas Medicaid. Medium. March 2016. Available at: https://medium.com/@txhealthplans/new-tahp-study-revealspotential-to-unlock-millions-in-savings-in-texas-medicaid-4c9dca8556f4. Accessed January 6, 2018.

18. Ngo KD. State of Texas Vendor Drug Program. Formulary control state vs. MCO. Texas Health and Human Services Commission. January 9, 2017. Available at: https://hhs.texas.gov/sites/default/files/formulary-control-statevs-mco.pdf. Accessed January 6, 2018.

19. The Lewin Group. Medicaid managed care cost savings - a synthesis of 24 studies. America's Health Insurance Plans. March 2009. Available at: http://www.communityplans.net/Portals/0/ACAP\%20Docs/AHIP\%20 Lewin\%20Study.pdf. Accessed January 6, 2018.

20. The Menges Group. Medicaid pharmacy savings opportunities: national and state-specific estimates. May 2013. Available at: https://www.themengesgroup.com/upload_file/final_medicaid_savings_report_menges_group_ may_2013.pdf. Accessed January 6, 2018.

21. Fairman KA, Motheral BR, Henderson RR. Retrospective, long-term follow-up study of the effect of a three-tier prescription drug copayment system on pharmaceutical and other medical utilization and costs. Clin Ther. 2003;25(12):3147-61.

22. Shirneshan E, Kyrychenko P, Matlin OS, Avila JP, Brennan TA, Shrank WH. Impact of a transition to more restrictive drug formulary on therapy discontinuation and medication adherence. J Clin Pharm Ther. 2016;41(1):64-69.

23. Hatter L. Facing losses, Florida Medicaid HMOs ask for rate hikes. WFSU Public Media. July 31, 2015. Available at: http://news.wfsu.org/post/facinglosses-florida-medicaid-hmos-ask-rate-hikes. Accessed January 6, 2018. 
The Effect of Florida Medicaid's State-Mandated Formulary Provision on Prescription Drug Use and Health Plan Costs in a Medicaid Managed Care Plan

\begin{tabular}{|c|c|c|c|c|c|c|}
\hline \multirow[t]{3}{*}{ APPENDIX } & \multicolumn{6}{|c|}{$\begin{array}{l}\text { Formulary Status of Prescriptions } \\
\text { Dispensed in Pre- and Postpolicy } \\
\text { Periods }\end{array}$} \\
\hline & \multicolumn{3}{|c|}{ Florida Health Plan } & \multicolumn{3}{|c|}{ Comparable Health Plan } \\
\hline & $\begin{array}{c}\text { Generics } \\
\%\end{array}$ & $\begin{array}{l}\mathrm{PB} \\
\%\end{array}$ & $\begin{array}{c}\text { NPB } \\
\%\end{array}$ & $\begin{array}{c}\text { Generics } \\
\%\end{array}$ & $\begin{array}{l}\text { PB } \\
\%\end{array}$ & $\begin{array}{c}\text { NPB } \\
\%\end{array}$ \\
\hline Prepolicy period & 87.7 & 5.0 & 7.3 & 86.9 & 12.7 & 0.4 \\
\hline Postpolicy period & 87.7 & 12.1 & 0.2 & 86.9 & 12.6 & 0.5 \\
\hline \multicolumn{7}{|c|}{$\begin{array}{l}\text { Note: A total of } 409 \text { and } 867 \text { unique National Drug Code numbers were dispensed } \\
\text { for members in the Florida health plan and comparable health plan, respectively, in } \\
\text { the pre- and postpolicy periods examined in this study (weighting to 220,623 and } \\
312,995 \text { prescription claims, respectively). } \\
\text { NPB = nonpreferred brands; } P B=\text { preferred brands. }\end{array}$} \\
\hline
\end{tabular}

\section{APPENDIX B Sample Selection Methodology ${ }^{a}$}

Total Medicaid members in the study period (January 1, 2014-June 30, 2015)

Temporary Assistance for Needy Families program members only

Members aged less than 65 years

Members with $\$ 0$ in out-of-pocket costs

Members continuously enrolled during prepolicy period (January 1, 2014-June 30, 2014)

and postpolicy period (January 1, 2015-June 30, 2015)

Matched Medicaid study sample with members eligible for full study period (pre and post)

Florida Health Plan n (\%)

122,212

$84,105 \quad(68.8)$

$78,688 \quad(93.6)$

75,541

13,839

$(96.0)$

$(96.0)$

$9,186 \quad(66.4)$

Comparable Health Plan n (\%)

aTable shows percentage retained from each criterion to the next; percentages are rounded to 1 decimal point. 